\title{
energies
}

ISSN 1996-1073

Correction

www.mdpi.com/journal/energies

\section{Correction: Energy Resources in the Future}

\section{Ken Tomabechi}

Former Research Advisor, Central Research Institute of Electric Power Industries, 4-15-14 Nakahara, Mitaka-shi, Tokyo, 181-0005, Japan; E-Mail: ken-toma@parkcity.ne.jp; Tel.: +81-0422-46-3326;

Fax: +81-0422-46-3326

Received: 30 April 2010 / Published: 11 May 2010

We found three errors in our paper published in Energies [1]. The corrections are as following:

(a) $25 \%$ in the ninth line from the bottom of page 688 should be $33 \%$;

(b) $\mathrm{Wm}^{-2}$ in the seventh line from the bottom of page 689 should be $\mathrm{W} / \mathrm{m}^{2}$;

(c) GW in the fifth line of page 694 should be GWe.

We apologize for any inconvenience caused to the readers.

\section{Reference}

1. Tomabechi, K. Energy Resources in the Future. Energies 2010, 3, 686-695.

(C) 2010 by the authors; licensee MDPI, Basel, Switzerland. This article is an Open Access article distributed under the terms and conditions of the Creative Commons Attribution license (http://creativecommons.org/licenses/by/3.0/). 